\title{
Kolonoskopi sırasında uygulanan iki farklı sedoanaljezi yönteminin dikkat, öğrenme, eve gönderme zamanı ve uyuma süreleri açısından karşılaştırılması
}

\author{
Comparison of the effect of two different sedoanalgesia methods on attention, learning, discharge \\ time, and sleep time over postoperative 24 hours
}

Hakan Ümit ÜNAL ${ }^{1}$, Ylldız KAYA², Coşkun ARAZ³ ${ }^{3}$, Murat KORKMAZ1 , Haldun SELÇUK ${ }^{1}$

Başkent Universitesi Tıp Fakültesi, ${ }^{1}$ Gastroenteroloji Bilim Dal, ${ }^{2}$ Nöroloji Anabilim Dall, ${ }^{3}$ Anestezi ve Reanimasyon Anabilim Dalı, Ankara

Giriş ve Amaç: Birçok merkezde gastrointestinal sistemin endoskopik işlemlerinde sedoanaljezi kullanımı rutin hale gelmiştir. Bu amaçla kullanılan ilaçlar, işlem sonrası takip süresinde uzamaya ve geçici bir süre dikkat ve ögrenmede bozulmalara neden olduklarından, hastalara gün içinde dikkat gerektiren işler yapmaması önerilir. Biz bu çalışmada; sedoanaljezi amacı ile kullanılan iki farklı protokolün hasta dikkat ve ögrrenme testleri üzerine etkisini ve her iki grup için ve işlem sonrasındaki 24 saatte hastaların uykuda geçirdiği süreleri karşılaştırmayı amaçladık. Gereç ve Yöntem: Kolonoskopi yapılmak üzere ünitemize başvuran hastalar sedoanaljezi tipine göre midazolam-meperidin ve meperidin-propofol gruplarnna randomize edildi. Hastalara işlem öncesi, işlem sonrası uyanma odasına alındıklarında ve işlem bitiminden 30 dakika sonra toplam üç defa olmak üzere, aynı nöroloji uzmanı tarafindan ögrenme ve dikkat testleri (iz sürme, Stroop ve Rey testleri) uygulandı ve sonuçlar sayısal veriler olarak not edildi. Çalışmanın sonunda her iki grubun eve gönderilme zamanları ve işlemden sonraki ilk 24 saatte uykuda geçirdikleri süre karşılaştırıldı. Bulgular: Çalışmaya 32'si midazolam-meperidin ve, 19'u meperidin-propofol grubuna randomize edilen toplam 51 hasta alındı. Çalışma grubumuzun ortanca yaşı 51 olup, 25 hasta kadın idi. Her iki grupta eve gönderilme zamanları ve 24 saatte uykuda geçen sure benzer idi ( $p=0.617$ ve $p=0.242$ ). Her iki grup için başlangıç testlerine göre değerlendirildiğinde işlem sonrası dikkat ve ögrenmede anlamlı bozulma olduğu izlendi ( $p<0.001$ ). Dikkat ve öğrenmedeki bozulma düzeyi her iki grupta benzerdi. Sonuç: Kolonoskopi sirasında midazolam-meperidin ve meperidin-propofol protokolleri ile uygulanan sedoanaljezi dikkat ve ögrenme üzerine aynı düzeyde olumsuz etki yapmaktadır.

Anahtar kelimeler: Kolonoskopi, sedoanaljezi, dikkat testleri, ögrenme testleri, derlenme zamanı
Background and Aims: Sedoanalgesia usage has become routine for gastrointestinal endoscopic procedures in many centers. Since the drugs used for this purpose may lengthen the recovery time or cause a temporary deterioration in learning and attention after the procedure, patients are cautioned to not undertake activities during the day that require their attention. In this study, we aimed to compare the effects of two sedoanalgesia protocols on learning and attention, discharge time, and sleep time over postoperative 24 hours in two groups. Materials and Methods: All patients referring to our unit for colonoscopy had been randomized prior to the procedure to either the midazolam-meperidine or meperidine-propofol group. Protocols were administered to all patients by the same neurology specialist three times (pre-procedural, immediately after being taken to the recovery room, and 30 minutes after the end of the procedure). Results were noted as numerical values. At the end of the study, the two groups were compared with respect to the discharge time and time asleep over 24 hours post-procedure. Results: Fifty-one patients were recruited to the study; 32 were randomized to the midazolam-meperidine and 19 to the meperidine-propofol group. The mean age of the study group was 51 years, and 25 patients were female. Both groups were similar regarding the discharge time and the sleep duration over 24 hours post-procedure $(p=0.617$ and $p=0.242)$. When the two groups were assessed in comparison to the onset, learning and attention tests were shown to have deteriorated significantly after colonoscopy in each group $(p<0.001)$. The deterioration in both attention and learning levels was similar between the two groups. Conclusions: Both midazolam-meperidine and midazolam-propofol sedoanalgesia protocols during colonoscopy demonstrated similar negative effects on learning and attention.

Keywords: Colonoscopy, sedoanalgesia, attention test, learning test, recovery time

\section{GİRIŞ}

Kolonoskopi her geçen gün kullanım sıklı̆ı artan ve alt gastrointestinal sistem (GIS) patolojilerinin değerlendirlmesinde altın standart kabul edilen yöntemdir. Ancak kolonoskopi işleminden beklenen fayda kolon temizlik düzeyi ve hastanın işleme olan toleransı ile ilişkilidir. Hasta toleransını arttırmak amacı ile birçok merkezde kolonoskopi işlemi sırasında sedoanaljezi uygulanmaktadır. Uygulanan sedoanaljezinin bu olumlu etkileri yanında, işlem sırasında özellikle kardiovasküler yan etkilere

bağlı komplikasyon riskini arttırması ve işlem sonrası takip ve monitörizasyon gerektirmesi hasta güvenliği ve işlem maliyeti açısından önemlidir. Sedoanaljezi amaçlı kullanılan ilaçların yağda çözünürlüğünün fazla olması hasta uyandıktan sonra oluşan tekrar dağllım (redistribusyon) etkisi nedeni ile hastalarda uyku halinin devamlllığına neden olabilmektedir. Buna bağlı olarak hastalarımıza ve yakınlarına endoskopi ünitesinden ayrilırken gün içinde dikkat gerektiren işler yapmaması önerilmektedir. 
Biz bu çalışmada; sedoanaljezi amacı ile kullanılan iki farklı protokolün hasta dikkat ve öğrenme testleri üzerine etkisini ve her iki grup için eve gönderme zamanı ve işlem sonrasındaki 24 saat içerisinde hastaların uykuda geçirdiği süreleri karşlaştırdık.

\section{GEREÇ ve YÖNTEM}

Bu çalışma Başkent Üniversitesi Tıp Fakültesi ve Sağlık Bilimleri Araştırma Kurulu ve Etik Kurulu tarafindan (Proje no: KA05/133) ve Başkent Üniversitesi Araştırma Fonu'nca desteklenmiştir.

Çalışmaya, 18 yaşını doldurmuş ve gastroenteroloji poliklinik muayenesi sonrasında kolonoskopi yapılma endikasyonu konmuş hastalar alındı. Bilinen nörolojik hastalığı olan hastalar ile hastanede yatan hastalar, tedavi amaçlı kolonoskopi yapılacak hastalar, kolostomisi olan hastalar, kolon cerrahisi geçirmiş hastalar, barsak temizliği yeterli olmayan, kronik alkol kullanımı olan hastalar çalışmaya alınmadı. Bunun yanında kolonoskopi işlemi sırasında sedoanaljezi uygulanmasını istemeyen hastalar da çalışma dışı bırakıldı. Çalışma hastalarına, hasta algı düzeyinin gün içinde değişkenlik gösterebileceği düşüncesi ile saat 09-11 arasında işlem yapıldı. İşlem, en az 2 yıl kolonoskopi deneyimi olan gastroenteroloji asistanı ve uzman gastroenterologlar tarafindan uygulandı. İşlem öncesinde hastalar kardiyak ve kan oksijen satürasyonları açısından monitörize olarak izlendi. Monitörizasyon, Alderete skorlama sistemine göre hastada yeterli derlenme sağlanana kadar devam ettirildi. Monitörizasyon sonlandırma kararı işleme eşlik eden anestezi uzmanı tarafindan alındi.

\section{Sedasyon protokolü}

Hastanın sedasyonu ve monitörizasyon takibi işleme eşlik eden uzman anestezist tarafından yapıldı. Tüm hastalara işlem sırasinda 2 litre/dakikadan nazal oksijen verildi. Hastalar uygulanacak sedasyon türüne göre randomize olarak meperidin-midazolam (MM) ve propofol-meperidin (PM) grubuna ayrildı. Tüm medikasyonlar intravenöz yolla yapıldı. Her iki gruba da midazolam başlangıçta $0.05 \mathrm{mg} / \mathrm{kg}$ dozunda uygulandı. Ardında MM grubunda meperidin $0.3 \mathrm{mg} / \mathrm{kg}$ dozunda uyguland. Ilave dozlar işlem sürecinde hasta takip kriterlerine göre anestezi uzmanı tarafindan uygulandı. PM grubunda ise $0.5 \mathrm{mg} /$ $\mathrm{kg}$ propofol indüksiyon dozu $0.05 \mathrm{mg} / \mathrm{kg}$ midazolamı takiben verildi ve propofol 3-5 dakikada bir $0.1 \mathrm{mg} / \mathrm{kg}$ dozunda titre edildi. Propofol preparatı olarak propofol disodyum edetate (Diprivan) kullanıldı. Maksimum dozlar: propofol için $5 \mathrm{mg} /$ $\mathrm{kg}$, meperidin için $1.5 \mathrm{mg} / \mathrm{kg}$ ve midazolam için $0.1 \mathrm{mg} / \mathrm{kg}$ olarak belirlendi.

\section{Nörolojik değerlendirme}

Çalışmaya alınan tüm hastalar işlemden hemen önce uzman nörolog tarafından değerlendirildi. Değerlendirme sonucunda algı düzeyi açısından çalışmaya uygun bulunmayan hastalar belirlenerek çalışma dışı bırakıldı. Çalışmaya dahil edilen hastalara işlem öncesi, işlem sonrası uyanma odasına alındığında ve işlem bitiminden 30 dakika sonra dikkat ve ögrenme testleri yapildi.

- Trail making A (iz sürme testi A) testinde puanlama; testi bitirme saniyesi ve hataların puanlanmasıly yapılır. Puan ne kadar artarsa işlevde o kadar kötüleşme olduğunu gösteririr.

- Stroop (kelime, renk, kelime renk bölümlerinden oluşur.) Stroop testinde 45 sn'de okunabilen kelime sayısı ve yapılan hatalar puanlandı. Puanın düşük olması işlevin kötüleştiğinin göstergesi kabul edildi.

- Rey sözel işitsel sözel öğrenme testi: Beş kez tekrarlanan 15 kelimelik listeden en fazla öğrenilebilinen kelime sayısı değerlendirildi. Puanın düşmesi işlevin kötüleştiğinin göstergesi olarak kabul edildi.

\section{Eve gönderme zamanı}

Alderete Skoruna göre 9 puana ulaşan hastalar için yakınları eşliğinde taburcu edildi. Eve gönderme zamanı, hastanın uyanma odasına alınma zamanı ile Alderete skoruna göre taburculuk kararının verildiği an arasındaki zaman farkının dakika olarak ifadesidir.

\section{4 saatlik uyku süresi}

Isşlemi asiste eden hemşire tarafından işlemden bir gün sonra hasta telefon ile aranılarak öğrenilen, işlem sonrası takip eden 24 saatte uykuda geçen toplam sürenin saat cinsinden ifadesidir.

\section{İstatistik}

Hastalara ait demografik ve klinik veriler SPSS 17.0 paket programı kullanılarak analiz edildi. Tüm veriler normal dağı-

Tablo 1. Ardışık uygulanan testlerde uygulama zamanına göre değişim

\begin{tabular}{|c|c|c|c|c|}
\hline & & Jygulama Zam & & \\
\hline Test & Önce & Sonra 1 & Sonra 2 & $\mathrm{p}$ \\
\hline Trail-a & $65.86 \pm 24.05$ & $81.29 \pm 35.92$ & $71.47 \pm 29.76$ & $<0.001$ \\
\hline Rey & $5.76 \pm 1.94$ & $4.07 \pm 1.76$ & $4.33 \pm 1.91$ & $<0.001$ \\
\hline Stroop & $36.66 \pm 10.66$ & $32.05 \pm 10.94$ & $35.66 \pm 12.43$ & $<0.001$ \\
\hline
\end{tabular}


Tablo 2. Öğrenme ve dikkat testlerindeki değişimin sedoanaljezi grupları arasında karşılaştırılması.

\begin{tabular}{|c|c|c|c|c|}
\hline \multirow{2}{*}{\multicolumn{2}{|c|}{ Test }} & \multicolumn{2}{|c|}{ Grup } & \multirow[b]{2}{*}{$P$} \\
\hline & & MP & MM & \\
\hline \multirow{3}{*}{ Trail-a } & Önce & $62.84 \pm 21.09$ & $67.65 \pm 25.80$ & 0.253 \\
\hline & Sonral & $84.73 \pm 39.96$ & $79.25 \pm 33.79$ & \\
\hline & Sonra2 & $73.68 \pm 31.36$ & $70.15 \pm 29.20$ & \\
\hline \multirow{3}{*}{ Stroop } & Önce & $35.68 \pm 8.73$ & $37.25 \pm 11.75$ & 0.230 \\
\hline & Sonral & $31.94 \pm 8.43$ & $32.12 \pm 12.32$ & \\
\hline & Sonra2 & $36.47 \pm 10.61$ & $35.18 \pm 13.54$ & \\
\hline \multirow[t]{3}{*}{ Rey } & Önce & $5.68 \pm 1.49$ & $5.81 \pm 2.19$ & 0.364 \\
\hline & Sonral & $4.05 \pm 1.54$ & $4.09 \pm 1.90$ & \\
\hline & Sonra2 & $4.63 \pm 1.64$ & $4.15 \pm 2.06$ & \\
\hline
\end{tabular}

MM: Midazolam-meperidin, Önce: işlem öncesi, Sonral: Hastanın uyanma odasına kabulünden hemen sonra, Sonra 2: Işlem bitiminden 30 dakika sonra

lım özelliği göstermediği için non-parametrik testler kullanıldı. $\mathrm{Bu}$ amaçla, sayısal verilerin analizi için Mann-Whitney U testi kullanıldı. Tekrarlayan ölçümlerde gruplar arası farkı değerlendirmek için iki yönlü varyans analizi kullanıldı. $\mathrm{P}<0.05$ olması istatistiksel olarak anlamlı kabul edildi.

\section{BULGULAR}

Çalışmaya MP grubundan 19, MM grubundan 32 olmak üzere toplam 51 hasta dahil edildi. Hastaların 25'i kadın, 26'sı erkekti ve ortanca yaş 51 (24-75 aralığında) idi.

Her iki grupta eve gönderme zamanı median 50 dakika idi ( $\mathrm{p}=0.617$ ). Bu süre MP grubu için 30-100 dakika arasında iken, MM grubunda 35-85 dakika aralığında idi. MP grubunda hastaların 24 saat içerisinde uykuda geçirdikleri süre median 10 saat (minimum 4, maksimum 18) iken, MM grubu için bu sürenin medianı 9 saatti (minimum 5, maksimum 14) $(\mathrm{p}=0.242)$.

Dikkat ve öğrenme ile ilgili nörolojik testler (İz sürme, Stroop, Rey) işlem öncesi, işlemden sonra hasta uyanma odasına alındığında (işlem sonrası 1) ve işlem bitiminden 30 dakika sonraki (işlem sonrası 2) değerlendirmeleri karşılaştırıldığında her bir test için fark istatistiksel olarak anlamlı idi (p<0.001) (Tablo 1).

Nörolojik testlerin tekrarlayan ölçümleri MP ve MM grupları için karşılaştırıldığında hiç bir test için anlamlı fark saptanmadı (Tablo 2).

\section{TARTISSMA}

Endoskopik işlemlerin sedoanaljezi ile yapılması işlem kalitesini, hasta ve doktor konforunu arttırmaktadır. Ancak bunun yanında, özellikle kardiyopulmoner komplikasyon riskinde bir artışı da beraberinde getirmektedir. Bu riskin gerçekleştiği hastaların \%90'ı Amerikan Anestezistler Derneği (ASA-American Society of Anesthesiologists) skoru III'ün üzerindeki hastalardan oluşmaktadır (1). Biz çalışmamıza ASA III ve üzerindeki hastaları dahil etmedik ve işlem sırasında oluşabilecek komp- likasyonların karşılaştırılması bu çalışmanın amacı dışındaydı. Daha önceki çalışmalarda midazolam ve propofolün komplikasyon riski, hasta tatmini ve hastanın işlemi hatırlama oranları karşılaştırılmış ve anlamlı fark saptanmamıştır (2-4). Bizim çalışmamızda bu iki ilacın dahil olduğu iki farklı hasta grubunda işlem öncesi ve sonrası dikkat ve öğrenme testleri ile eve gönderme zamanı ve işlem sonrası 24 saatlik sürede uykuda geçirilen süre karşılaştırılmıştır.

Sedoanaljezi ile yapılan endoskopik işlemlerde komplikasyon riski sadece işlem sırasında artmamaktadır. Hastanın eşlik eden hastalıkları yanında kullanılan ilaç ve dozlarına bağlı olarak işlem sonrası derlenme sırasında da hipoksi başta olmak üzere komplikasyonlar gelişebilmektedir. Bu komplikasyonların minimuma indirgenmesi ancak hastaların derlenme odasında uygun süre takibi ile olabilir. Bu takip süresini belirleyen ve hasta için uygun eve gönderilme zamanını tespit etmede yardımcı olan skorlama sistemleri geliştirilmiştir. Biz çalışmamızda Alderete Skorlamasını kullandık ve 9 puana ulaşan hastalar için eve gönderilebilir kararı verdik. Eve gönderme zamanı açısından iki sedoanaljezi protokolü (MM ve MP) arasındaki fark anlamlı değildi $(\mathrm{p}=0.617)$.

Eve gönderilme kararı verilen hastalara 24 saat boyunca dikkat gerektiren işler yapmaması ve özellikle araba kullanmamasl genel kabul gören bir öneridir. Hastaların 24 saat boyunca dikkat gerektiren iş yapmaması demek o gün için işe gitmeyip dinlenmesi anlamına gelmektedir. Bu durum, işlemin yapılma sıklığı göz önüne alındığında ciddi bir iş gücü kaybı demektir. Jonas ve arkadaşlarının yaptığı çalışmada sedoanalji uygulanarak yapılan kolonoskopi sonrası hastaların rutin hayata dönme süreleri ortalama 15.8 saat, sedasyon verilmeden yapilan kolonoskopilerde bu süre ortalama 1.8 saat olarak bulunmuştur (5). Japonya'da yapılan ve propofol monoterapisi kullanılan bir çalışmada ise, sedasyon ile endoskopi yapılan hastaların işlem sonrası araba kullanmasının risk yaratmadığı belirtilmiştir (6). Biz bu çalışmada işlem öncesi ve sonrası yaptığımız nörolojik testleri karşılaştırdığımızda her iki protokol için dikkat 
ve ögrenmede anlamlı bozulmalar saptadık ( $<<0.001)$. Buna göre, hastaların işlem sonrası araba sürmek ve benzeri dikkat gerektirecek işleri yapmaması ve taburculuğu sırasında mutlaka bir refakatçisinin bulunmasının gerekliliğini bir kez daha ve nörolojik testler ile gösterdik. Dikkat ve ögrenme ile ilgili bozuklukları her iki hasta grubunda da benzer bulduk. Isslem sonrasındaki 24 saatte hastaların uykuda geçirdikleri süre de her iki grupta benzerdi.

\section{KAYNAKLAR}

1. Thompson AM, Wright DJ, Murray W, et al. Analysis of 153 deaths after upper gastrointestinal endoscopy: room for improvement? Surg Endosc 2004;18:22-5.

2. Carlsson U, Grattidge P. Sedation for upper gastrointestinal endoscopy: a comparative study of propofol and midazolam. Endoscopy 1995;27:240-3.

3. Chin NM, Tai HY, Chin MK. Intravenous sedation for upper gastrointestinal endoscopy: Midazolam versus propofol. Singapore Med J 1992;33:478-80
Sonuç olarak, günlük endoskopi pratiğinde sık olarak kullanılan iki sedoanaljezi yönteminin dikkat ve öğrenme üzerine etkisini karşılaştırdığımızda gruplar arasında fark saptamadık. Ancak her iki protokolün de dikkat ve öğrenme üzerine başlangıç değerlerine göre anlamlı bozulmaya neden olduğunu gösterdik. Buna göre hastalara işlem sonrası dikkat gerektiren işlerden kaçınmaları yolundaki önerimizin yerinde olduğunu nörolojik testler ile de destekleyerek göstermiş olduk.

4. Patterson KW, Casey PB, Murray JP, et al. Propofol sedation for outpatient upper gastrointestinal endoscopy: comparison with midazolam. Br J Anaesth 1991;67:108-11.

5. Jonas DE, Russell LB, Sandler RS, et al. Patient time requirements for screening colonoscopy. Am J Gastroenterol 2007;102:2401-10.

6. Horiuchi A, Nakayama Y, Hidaka N, et al. Low-dose propofol sedation for diagnostic esophagogastroduodenoscopy: results in 10,662 adults. Am J Gastroenterol 2009;104:1650-5. 